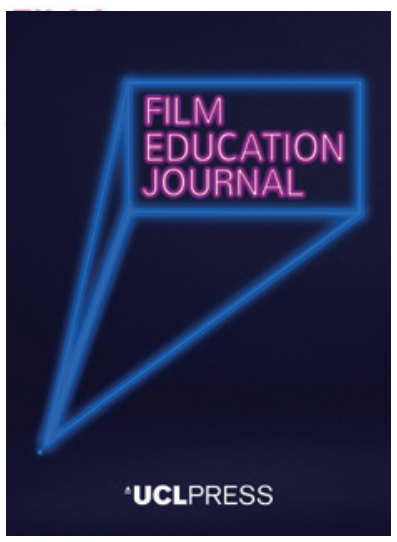

UCLPRESS

FILM EDUCATION JOURNAL

ISSN 2515-7086 (Online)

Journal homepage:

https://www.uclpress.co.uk/pages/film-education-journal

\title{
Consolidating an experimental pedagogy: Exploring ecologies of film education within France's Cinéma Cent Ans De Jeunesse and Scotland's Understanding Cinema project(s) between 2013 and 2019
}

Jamie Chambers iD

\section{How to cite this article}

Chambers, J. (2020) 'Consolidating an experimental pedagogy: Exploring ecologies of film education within France's Cinéma Cent Ans De Jeunesse and Scotland's Understanding Cinema project(s) between 2013 and 2019'. Film Education Journal, 3 (2), 138-59. Online. https://doi.org/10.14324/FEJ.03.2.03

Submission date: 12 March 2020

Acceptance date: 12 May 2020

Publication date: 26 November 2020

\section{Peer review}

This article has been peer-reviewed through the journal's standard double-blind peer review, where both the reviewers and authors are anonymized during review.

\section{Copyright}

(C) 2020 Chambers. This is an open-access article distributed under the terms of the Creative Commons Attribution Licence (CC BY) 4.0 https://creativecommons.org/licenses/by/4.0/, which permits unrestricted use, distribution and reproduction in any medium, provided the original author and source are credited.

\section{Open access}

The Film Education Journal is a peer-reviewed open-access journal. 


\title{
Consolidating an experimental pedagogy: Exploring ecologies of film education within France's Cinéma Cent Ans De Jeunesse and Scotland's Understanding Cinema project(s) between 2013 and 2019
}

\author{
Jamie Chambers* - University of Edinburgh, UK
}

\begin{abstract}
The Cinémathèque Française's long-running Cinéma Cent Ans De Jeunesse (CCAJ) has become one of the most influential film education projects in the world today. This article reflects critically and in detail upon five years of the delivery of the project in Scotland, considering the changing pedagogical shapes of the project's 'curriculum' alongside changing ecological factors (such as class size and age and lesson time) in considering how a small nation such as Scotland might best employ CCAJ as a means of addressing foundational film education.
\end{abstract}

Keywords: understanding cinema, Cinéma Cent Ans De Jeunesse, Scotland, Alain Bergala, Andre Bazin, small nation, filmmaking with young people

\section{Introduction}

It would seem no understatement in 2020 that the Cinémathèque Française's longrunning Cinéma Cent Ans De Jeunesse (CCAJ) has become one of the most influential film education projects in the world today. It was founded in 1995 by Alain Bergala, whose work was explored by various commentators in the inaugural issue of the Film Education Journal (Burn, 2018; Chambers, 2018; Gibbs, 2018; Henzler, 2018; Reid, 2018), and since (Eckert and Martin, 2018; Donald, 2019; Slatinšek, 2020); as well as in Cannon (2018) and Nathalie Bourgeois. CCAJ was delivered for the first decade of its life within France 'across ... grades one through twelve ... from several regions of France and diverse social backgrounds' (Bergala, 2016: 48). CCAJ subsequently expanded to welcome international collaborators from Spain (at the initial request of Nuria Aidelman from non-profit organization A Bao A Qu) and latterly from Portugal, Italy, and - later still - the United Kingdom. While unintentional, this internationalism was perhaps inevitable, emerging, as Bourgeois has described, from a sense of 'loneliness' among film education practitioners, 'because people doing things in different places ... felt lonely and ... wanted to be together' (Conversation with author, 2016). At the time of writing, CCAJ now takes place annually in Argentina, Brazil, Bulgaria, Chile, Colombia, Germany, India, Italy, Japan, Lithuania, Mexico, Portugal, Spain, the United Kingdom and Uruguay - making it probably the world's most globally influential film education project.

CCAJ is delivered within an annual cycle whereby, within a given school year, all participating classes and groups worldwide 'delve into a single topic in cinema studies' (Bergala, 2016: 48) or 'question of cinema' (Cinéma Cent Ans De Jeunesse, 2020), 
such as 'Colour', 'The Long Take' or 'The Place of Reality in Fiction'; such nodes of confluence, intersecting a diverse body of cinema, subsequently provide a shared focus of enquiry that guides participants through project work in diverse learning environments. Bourgeois believes this annual topic is central to CCAJ's endeavours to bridge its locality of origin with the increasing globality of its delivery, describing to delegates at A Bao A Qu's 2017 Moving Cinema conference (Aidelman and Colell, 2018) how the specificity of CCAJ's annual topic functions as a 'red thread' for participants of all ages and in diverse international contexts to find their way through the project.

With direction from Bergala as 'creative lead', CCAJ's team formulate the project's annual theme, alongside a corresponding set of exercises (entitled 'Rules of the Game') to be followed by all participants, and a body of clips assembled from world cinema to serve as illustration and embodiment of the theme. Participants subsequently congregate with their international co-investigators at three points in the year: in September, when the theme is announced and explored by adult participants through lectures and screenings led by Bergala; a mid-point meeting in mid-spring where adult participants gather again to share the exercises completed thus far; and a final, climactic series of screenings in June, attended by both child and adult participants to share short (approx. 10-minute) films representing the culmination of their exploration of CCAJ's annual topic throughout the year. As discussed later in this article, adults are as much part of CCAJ's learning process as children, leading to different, and at times divergent, registers or vocalities within the project. Generously, participation in CCAJ is free, although there is an expectation that participants will be able to cover the various costs - equipment, staffing, travel - involved with participation.

I first encountered CCAJ in 2013 as one of the film education practitioners tasked with delivery of its Scottish instantiation, Understanding Cinema. The Edinburghbased Centre for the Moving Image (CMI; responsible for Edinburgh International Film Festival (EIFF) and Filmhouse, Edinburgh's principal art-house cinema) began to participate in CCAJ in 2012/13. While the shape of its involvement has changed at several junctures since, $\mathrm{CMI}$ continues to participate in CCAJ at the time of writing.

From the five years I subsequently spent delivering CCAJ's annual 'curriculum' in both primary and secondary classrooms across Edinburgh and East Lothian, I can attest that CCAJ is (or at least has the potential to be) the most visionary, lucid and stimulating film education initiative I have yet encountered. Not only does CCAJ's pedagogy offer interlocking, inseparable experiences of making alongside watching films (meeting the imperative voiced by UK media studies scholars for literacy-building involving learning how to read and write; see Buckingham, 2003: 49; Burn, 2018: 53) but also a deep involvement with international film culture through its theme and its curated film clips. At moments, I have marvelled at CCAJ's ability to open up intellectually stimulating opportunities for children to engage with some of the most fundamental questions of cinematic aesthetics, such as when I witnessed 9-year-old children engaging with significant levels of comprehension - with practical explorations of the Bazinian aesthetics of cinematic time and the long take in 2013/14. Where other, more visible UK-based film education projects seem content merely to shoehorn film into school classrooms by any means necessary (usually instrumentalized in the service of other subjects such as history), to serve as relatively unreflective spaces of endorsement for the UK film industry, or offer introductions to film practice that - reflecting Bergala's (2016: 40) criticisms of 'cultural amnesia'- would seem to take place within a historical and cultural vacuum, CCAJ offers the possibility of opening up real opportunities for children within diverse learning environments to have a holistic engagement with film culture. 
This article adopts a semi-longitudinal perspective in reflecting in detail upon three editions of CCAJ through in-depth case studies, with further briefer mention of two subsequent editions beyond that. During this five-year period, there have been sufficient annual changes to the ecologies of the learning environment in which Understanding Cinema has taken place (primary classrooms, secondary school classrooms, afterschool clubs), the nature of its participants (class sizes, ages and dispositions) and most significantly, perhaps - within the changing nature of CCAJ's annual curricula, to afford certain conclusions regarding the effect of complex ecological factors upon the strength of resulting pedagogy. I have elsewhere considered the manner in which the ambient or, recalling Bachmann and Zahn (2018), ecological factors of a given film education project generate contingent degrees of affordance regarding the scope of possibility for learning within a given film educational encounter. Considering Bergala's theory of 'disruption', I have written of the 'small, intimate and localized disruptions created when we open up access for one student to intervene subjectively into the ongoing dialectic of global cinema' (Chambers, 2018: 49). Such an image serves here as a useful analogy for the moments when a given film education pedagogy is able to open up a moment of conscious, considered agency for a given learner; a moment when a student is able to make informed, self-aware creative decisions, such as being able to understand the difference between different approaches to framing a shot, and - having weighed up their relative merits - choose the option they want. These are always the moments I have reached for as a film education practitioner, enabled or hindered by the relative affordances and constraints generated by a given ecological context.

Inevitably, an ambitious international project such as CCAJ also involves a significant degree of interpretation, both on the part of local institutions such as CMI receiving their directives from the Cinémathèque Française, and from individuals like myself subsequently interpreting CCAJ's educational brief formally and informally across different learning environments with very different groups of learners. Every local instantiation of CCAJ thus involves literal and figurative processes of translation, shaped both by convergent and divergent responses to CCAJ's original brief. Borrowing from Alexis Nuselovici's notion of a 'culture of translation', Mark Reid (2018: 13) has discussed the 'translatability' of CCAJ as offering 'a vision of transnational cooperation through film that is not subject to jurisdiction, that is self-regulating, open access, generous, and tolerant, while still being coherent and critical'. Within such moments of translation, interesting cultural and epistemological tensions emerge, regarding not only divergent conceptions of cinematic aesthetics (Chambers, 2018: 47) but of pedagogy, both at a macro level (between nations), and a micro level (between different film education practitioners working within the same city). While CCAJ arguably merits Reid's utopian framing, its compelling construction of an international, semi-'universal' forum risks - like Bergala's work more generally - obscuring the extent to which the conceptions of cinema underlying CCAJ's annual topic, and the authoritative voices within discussion events, are rooted in a very particular, contingent conception of this media (Chambers, 2018: 45).

Considered over a five-year period, I argue CCAJ's approach exhibits a number of significant difficulties, relating in particular to its tendency to wander from the primary parameters of cinema, of competing adult/child registers within the project, and of the implicit presumption children come to the project already equipped with some understanding of cinema. Here it is necessary to elaborate upon some of the contingencies informing my perspective within a Scottish field of film education. A series of critical commentators over the past four decades have successively bemoaned 
the lack of a healthy film culture within Scotland: following the seminal critiques of Scotch Reels (McArthur, 1982), film critic Mark Cousins (2006: 10) proclaimed 'Scotland is not one of the world's great cinematic cultures and may never be', with acclaimed film producer Gillian Berrie arguing further that 'film [in Scotland] is in a terrible state and has been for some time' (Scottish Parliament, 2013: 3006). In 2020, while the prognosis for growth in Scotland's film and TV sector seems more hopeful, following Screen Industries Skills' 'Preparing for Growth' event at EIFF 2019 (Skills Development Scotland, 2019), significant doubts remain as to the correlation between industrial growth and cultural health - both as pertains to indigenous filmmaking activity and broader national engagements with film culture.

Within this somewhat depressed context (and correspondent desires to address such issues early on through film education), CCAJ has appeared to some (myself included) as a potential vehicle through which to embed an active and holistic engagement with film education early in life through Scottish schooling experiences. As I will argue, CCAJ's prioritization of an open-ended, experimental mode has made it an awkward and at times inefficient means of establishing a securely rooted film education programme within a small nation. Reflecting Bergala's often laudable predilection towards the asystematic (Chambers, 2018: 42), CCAJ displays little interest in instituting a consolidated, systematized curriculum, presenting itself instead as 'experimental pedagogy' (Gibbs, 2018: 91) or 'laboratory' (Nathalie Bourgeois, in conversation with author, 2016) that each year embarks upon a new, relatively openended course of cinematic enquiry; an 'educational adventure' (Cinéma Cent Ans De Jeunesse, 2020) in which everyone - founders, teachers, filmmakers and students - is continually exploring virgin territory.

As Bourgeois has stated:

We never repeat things. When we begin a year with a question, we don't know what will be found, what will be the reflection, pedagogical, learning. It is research for everyone - for children, but also for adults... And so we can do it again? No. For me, that's why this is a living project, because it's different for each participant, who comes to the project to find something and bring something. (Conversation with author, 2016)

CCAJ rarely recycles any aspects of content, let alone repeats a year, making it an at times frustrating vehicle through which to attempt sustained engagements with schools, given scant opportunities to consolidate and build confidence in practice. While there is a danger here of accusing a square peg of not fitting into a round hole (CCAJ was not developed for the purposes some of us hoped it might serve in Scotland), the criticisms that emerge from this contingent perspective are relevant beyond a Scottish context, for broader applications of CCAJ and film education pedagogy more generally.

Observing the changing ecologies as a reflective practitioner of Understanding Cinema over five years has given me much to reflect upon regarding the optimal structures and ecologies for classroom-based approaches to film education pedagogy. In mounting a critical consideration of CCAJ during this period, this article both draws upon and concludes a chapter of previous research surrounding my work with the project from 2013 to 2019; consisting, in particular, of an evaluative response to Bergala's The Cinema Hypothesis (2016) and the affordances his cine-pedagogy may generate for an emergent field of film education globally (Chambers, 2018); a case study of the project in action at Granton Primary School in 2017/18 (Donnelly et al., 2018); a consideration of the affordances CCAJ's advocacy of neorealist film 
technique may create for Scottish school students to foster greater self-efficacy and cultural agency (Chambers, forthcoming); exploring my initial year of involvement in 2013/14); and an early, auto-ethnographic exploration of the role of co-creation in Understanding Cinema and beyond (Chambers, 2019). While seeking to declare the partialities and located preoccupations of my own point of view, I provide both a celebrative and critical reflection upon five years of CCAJ and - in doing so - present certain observations arising from longer-term perspectives upon the shifting ecologies of the project over that period.

The following sections detail a series of relatively in-depth case studies of my work with Understanding Cinema between 2013 and 2017, considering how CCAJ's pedagogical brief and the ecological contexts in which I found myself working generated both affordances and limitations for the educational encounters within Understanding Cinema, before going on to draw some broader conclusions as to what might be gleaned with regard to the optimal conditions for film education pedagogy from CCAJ throughout this period.

\section{Understanding Cinema 2013/14: 'The Long Take'}

In my first year working with Understanding Cinema, I worked with a P5 class (9-10 year olds) at Law Primary School in a relatively affluent area in East Lothian; a P7 class (11-12 year olds) at St Gabriel's Primary School in a relatively disadvantaged area of East Lothian; and an after-school film club comprised of students from S4 to S6 (16-18 year olds) at Broughton High School in central Edinburgh. I worked with each class once a week for between 90 minutes to 2 hours, within a relatively compressed time frame from late November in 2013 until mid-June in 2014. In each setting I worked with a figurehead teacher: the class teacher in the case of the primary schools, and the school media studies teacher at Broughton. Sessions tended to be led by me, with a degree of supportive, collaborative input from the teacher, Understanding Cinema's explicit intention being that teachers should benefit from the specialist input of a filmmaker in the classroom along with their students. At Law and St Gabriel's we used small 'FlipVid' cameras the school already owned, and both purchased cheap ( $f 20$ ) tripods at my suggestion. Having already a history of strong media studies provision, Broughton High School already had their own HD camcorders that our students were able to use.

Funded through Creative Scotland's Creative Futures fund, 2013/14 has been to date - Understanding Cinema's most expansive year of provision, taking place across Scotland in Edinburgh, Glasgow, Dundee, Aberdeen and the Isles of Lewis and Mull. The theme was 'The Long Take', focusing upon an exploration of the expressive potential of unbroken shots within world cinema.

The 'Rules of the Game' comprised:

1. Students making a 'Lumière Minute', an exercise in which each participant across CCAJ shot a 60-second documentary from a static perspective.

2. Students in groups shooting a brief (2-3-minute) scene in one long take that was filmed twice, from both a static and a moving camera perspective. These two versions of the scene were intended to correspond to a typology of long takes provided by CCAJ (under headings such as 'double focus', 'changing during the shot') and the exercise came with the additional specification that 'particular attention will be paid to the use of sound in this exercise'.

3. Finally, participants being asked to make a group film (8-10 minutes) featuring several long takes, around the notion of a 'troubling encounter'. A further 
specification was provided that 'in one of the Long Takes the camera must forget the character or characters and become autonomous, follow another path and then find the character or characters again. This section should create an emotional or sensational response in the viewer watching the clip.'

As explored in detail elsewhere (Chambers, forthcoming), 2013/14 was arguably the most successful edition of Understanding Cinema during my time participating in the project. A crucial element of this success, upon reflection, relates to CCAJ's annual theme. 'The Long Take' provided a means for participants across a wide age range to engage both as viewers and filmmakers with fundamental questions of cinematic aesthetics. Through the ways in which it allowed children to think about the rendering of time in cinema, camera placement and movement, the careful evolution of a sequence shot through blocking, pacing and direction of an audience's attention, and the utilization of background, middle ground and foreground parts of a frame (to create the illusion of depth in two-dimensional images), 'The Long Take' allowed participants to plug themselves directly into the fundamental ontology of cinema, gaining a real sense of purchase of the primary modalities of filmmaking. The notion of a shot that did not cut (which also helpfully limited the need for any editing) was relatively easy to understand for all ages, while simultaneously allowing for significant depth and breadth of exploration. While with my older students at Broughton I gently introduced aspects of Bazin's aesthetics of realism and theories of cinematic time, I addressed the same aesthetic principles with 9-12-year-old pupils at Law and St Gabriel's, here guiding students instinctively through practice without the same degree of reflexive vocabulary. The resulting level of comprehension can be seen equally in Broughton's taught, urgent final film Wednesday, where long takes are used to explore the spiralling, situational horror of a school shooting, or Law's Blue Raspberry, a poetic account of growing tensions with parents where each scene is achieved in one shot, or St Gabriel's $L<3 B$, which opens with a bruisingly emotional long take in which the film's central character waits for the girl he likes, attempts to ask her out, and then is left alone, smarting from the knock-back.

The Lumière Minutes exercise in particular proved a lucid, easily comprehensible and pedagogically focused task (Chambers, forthcoming): students were challenged to document a minute of their experience, from a static camera position, to produce a film worthy of sharing with an audience. Here the learning objective was clear and easy to grasp for students, and the exercise afforded opportunities to begin thinking about camera placement and address some of the rudiments of camera technique young children often first struggle with in filmmaking work (in terms of not moving the camera, not talking during the shot, setting up the tripod in such a way the resulting shot wasn't crooked and filming in such a manner that those being filmed did not directly acknowledge the camera).

Throughout my time with Understanding Cinema, one of the central pedagogical challenges - particularly with younger children - has been thinking about how to help learners develop a sense of self-awareness as to the effects of camera placement. Frequently I have found students new to filmmaking will either wave the camera around, recording relatively indiscriminately as if they were using a smartphone, or when encouraged to use a tripod - simply plonk the camera down at eye level wherever they are currently standing (thus allowing relatively arbitrary factors to dictate their mise en scène). In my first year working with CCAJ, I discovered it was crucial to establish a rhythm whereby practical work was viewed and discussed with the group quickly enough after the material had been filmed for participants to remember their experiences. I frequently sought to structure sessions so that I began with input on 
the day's brief (approx. 45 mins), then allowed participants to go and shoot in various settings within the school grounds (approx. 45 mins), before finally the group watched and discussed the results together (30 mins).

Equally important was allowing students opportunities to repeat exercises and re-encounter the same exercise brief, now that they were hopefully equipped with heightened awareness as to the likely results of their decisions. If we consider how camera placement requires the intersection of thinking in the past tense ('what happened last time I tried to film this?'), present tense ('how does what I did in the past, and what I want an audience to see in the future, inform what I should be doing now?') and future tense ('how is an audience going to respond if I put the camera here?'), we can perhaps appreciate just how complex a skill this is both to teach and to learn. It is worth noting here that a significant number of my current film practice students at both undergraduate and postgraduate level similarly struggle to develop sufficient levels of self-awareness in their approach to camera placement. It is therefore all the more remarkable that, through the lucid approach of CCAJ which - at its best seems able to cut incisively through layers of aesthetic and discursive complexity to find direct pathways for young learners, I saw 9 year olds at Law in 2013/14 begin to develop a real, secure sense of awareness within these parameters, as manifest in particular within Blue Raspberry's considered camera placement, shot entirely outside school without my involvement (see Figure 1).

An element of divergence in my delivery of Understanding Cinema compared with colleagues elsewhere in Scotland arose between our respective approaches to Exercise 3, CCAJ's cumulative short film project. While many of my peers conceived of one film (consciously structured to involve the whole class either in front or behind the camera), I chose to encourage each of my classes to work in small groups of four

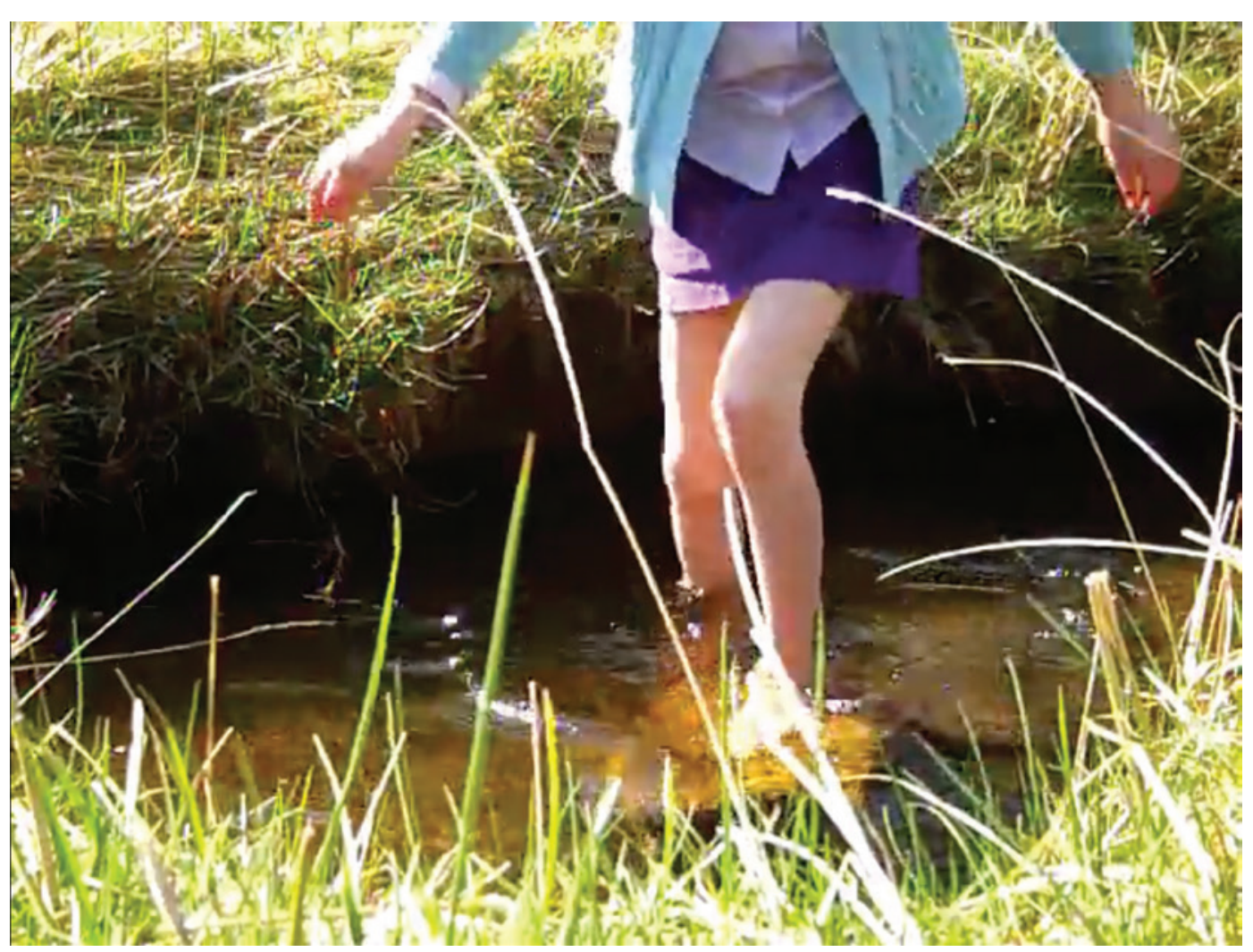

Figure 1: Poetic framings in Blue Raspberry 
or five students from a relatively early stage in their work with CCAJ. These groups each subsequently developed a film project for the final exercise in the 'Rules of the Game', meaning that there were on average four or five prospective projects in development per class/school. As we neared the project delivery deadline (for either the one Scottish film to be screened at Paris as part of the CCAJ screenings at the Cinémathèque Française, or the greater number of films screened as part of Understanding Cinema's screening event(s) at the EIFF), I would - in conversation with the class teacher - identify the films likely to be finished in time for the deadline and to the highest standard, and provide additional input during the shoot (often working with a group for two full days) to get these films ready on time. Across the five years I worked with Understanding Cinema, I found we almost always ran out of time for participants to edit films themselves, and therefore I tended to edit the films myself, sharing cuts where possible with groups for their approval and feedback (Chambers, 2019: 37, 39-40). In 2013/14, not only the films receiving additional attention from me, but all remaining films within each class, were completed. This aspect of Understanding Cinema subsequently served as something of a litmus test in indicating the confidence and motivation of CCAJ's participating teachers in finishing their own work: in years in which the project seemed to be working well, participating teachers usually found ways of finishing the other films themselves with a minimum of input from me. Contrastingly, in years when the project was not seemingly functioning as successfully, these films would unfortunately remain unfinished, as was to be the case the following year of my involvement.

I added further parameters of my own to supplement CCAJ's 2013/14 methodology. Inspired by the Bazinian aesthetics implicit in 'The Long Take', I began to pursue an approach to story development that drew upon aspects of global neorealist technique (Giovacchini and Sklar, 2011). I would lead story development sessions with small groups of students, encouraging them to draw upon their own experiences and eschew aspects of relative artifice in pursuit of an aesthetics of realism or naturalism, writing either about themselves and places that they knew, playing characters close to their own experience and using their own voices instead of adopting accents (Chambers, forthcoming). I gathered information on nearby locations of significance for the students (such as that featured in Law's The Den; or the school locations throughout First Day, and Blocked) that were available to film in. Informed by my own experiences working as a filmmaker with non-actors, I encouraged students to improvise their own dialogue, finding this tended to result in more naturalistic performances than was usually afforded by pre-written lines recalled from a script. Instinctively, participants began to reconcile aspects of their own lives with cinema, using places they knew, their own names and playing versions of themselves.

A teacher at St Gabriel's subsequently described this:

I think it was because the kids were tasked to make it as realistic as possible, and when we spoke about that as a group, we kind of said 'you need to use what you've got'. So immediately, it was going to be characters their own age, they were going to use pre-existing settings ... the likes of the school building, going down the street, someone's house: this was all available to them and it's immediately authentic. And I think they then just naturally began to use their own names ... I think that they've just taken it all very personal and it comes over in the film that it's personal issues and that it's realistic. I think by saying to them that the films had to be realistic, that was a breakthrough moment. At that point, they started to really take it seriously, and it has shone through. (Chambers, forthcoming) 
While my initial appeals to neorealist technique were largely pragmatic, stemming from a prediction students were more likely to achieve both realizable film projects and convincing aesthetics if they drew upon material more readily available to them, this approach also produced unexpectedly positive consequences for children's sense of self-efficacy and development of emotional literacy. Exploring issues and experiences from their own lives, and subsequently seeing themselves on screen, seemed in many instances to be a significantly empowering experience (perhaps relatable to the apperception of Lacan's (1978) 'mirror stage'), which in key instances led to remarkable strides in students' social confidence and educational attainment. In one instance, a student playing a central role in one of St Gabriel's film productions leapt forward three years in reading literacy, spelling age and social self-confidence, a development their teacher linked directly to the increased sense of agency they had developed by participating in the film project (Chambers, forthcoming). Such strong vindications both for personal development and quality of output led me to subsequently adopt similar aspects of neorealist technique for the entirety of my time working with Understanding Cinema (as discussed further later in this article in relation to the remarkable series of films produced between 2015 and 2019 by Granton Primary School).

Finally, for a small number of students who had had particularly powerful engagements with the Lumière Minutes exercise, I created an additional, extra-curricular activity to take place at home outside class time, encouraging individual students to conceive of small, semi-fictional narratives to lace in between the documentary modality of their Lumière Minutes exercise. Targeted in particular at participants who seemed able to work on their own, this exercise served to assist students in further exploring an aesthetics of naturalism, reconciling the tone of fictional narratives (both in terms of acting and mise en scène) with documentary footage through processes of montage and suture. This produced arguably the strongest work across any of my groups in the project, in particular Blue Raspberry and Me and Mum, two films directed by 9 year olds, which, interweaving aspects of documentary and fiction, display a significant degree of maturity and aesthetic comprehension.

Overall, my first year of working with Understanding Cinema afforded a glimpse into how a well-designed pedagogy within a functional ecology (in terms of class size, sufficient school support and class time) could allow simple, yet deep access to cinematic aesthetics yielding fairly remarkable results. Unfortunately, the subsequent year was to provide contrasting lessons in how less functional pedagogical and ecological factors could result in considerably less successful learning conditions within the bounds of the same project.

\section{5/16: 'Climate/Weather'}

Petra Slatinšek (2020: 83) has written elsewhere in the Film Education Journal as to the precarity of film education projects at the mercy of changing funding priorities, and the subsequent discontinuities accompanying requirements to regularly reapply for core funding. In 2014/15, Understanding Cinema found itself a casualty of changing funding structures at Creative Scotland, when the Creative Futures fund from which it had received funding in 2013/14 was discontinued. The project subsequently rebooted on a significantly reduced basis in 2015/16, the only participating schools now in Edinburgh and Dundee. In my second year of involvement I worked with a P7 class (11-12 year olds) at Granton Primary School, a P7 class at St Mary's Roman Catholic School in Leith, a P5 class (9-10 year olds) at St Joseph's Primary School in Saughton and an S4 media studies class (15-16 year olds) at Wester Hailes Education 
Centre (WHEC) - all schools in relatively disadvantaged parts of Edinburgh. In contrast to the expansive delivery of Understanding Cinema 2013/14, given a reduced level of funding and a stipulation from Creative Scotland that provision needed to reach a greater number of schools (in particular with schools in postcode areas high on the Scottish Index of Multiple Deprivation), I visited classes every second week, in the understanding I would set tasks for teachers to lead themselves in the weeks I was not present. Here, it was hoped, teachers would move beyond the more passive collaborative roles they had had in 2013/14 to participate more actively in the project, with specialist practitioners focusing more on delivery of content and the subsequent review of footage. I soon found this approach created an unfortunate sense of 'sink or swim', whereby more confident teachers thrived upon the imperative to become more actively involved, whereas less confident teachers found themselves increasingly overwhelmed. At one school in particular I was paired with a probationary teacher who had not signed up for the project, but had been volunteered by a senior member of staff. Here, the teacher I was working with - understandably anxious to meet curricular requirements in their probationary year - was very hesitant regarding the amount of class time they felt able to devote to the project. The time I was able to spend with classes thus varied considerably school to school, with generous allocations (2 hours or more) in some schools, and highly straitened ones (45 minutes) in others.

Discussing the project after its conclusion with participating teachers in 2016, each one described the level of specialist knowledge CCAJ seemed to require of them as intimidating. This was particularly the case regarding technology, as one teacher described:

I think the main thing I struggled with was at the beginning that I didn't have a clue what I was doing, so I felt like just even working the camera and stuff like that, I really didn't know. So, I think it was more me, that I lacked confidence than anything else. (Conversation with author, 2016)

I frequently found that, in several of the schools, I would arrive to find the class had been unable to complete the exercises set two weeks previously. While not wishing to underestimate the importance of classroom teachers as essential collaborators in the learning process, it is worth emphasizing here CCAJ's core belief as to the importance not only of the filmmaker in the classroom, but of sustained, immersive content between filmmaker and students. Bergala describes that it is precisely the 'externalness' of the filmmaker that is her/his strength in the classroom:

This arrival in the classroom of people from the film industry redistributes the cards and brings new values that allow some students to see recognition of their skills and qualities they had never been able to show inside the institution. It is good for everyone: the teacher, students, and the film practitioner. The atmosphere of the school is thereby transformed. (BFI Southbank, 2017)

This was echoed by one of the participating teachers:

It's so valuable for [my students] to have somebody who's not a teacher, ... an adult who has another occupation, who has a different influence on them ... It ... gives them a different experience. They're never going to meet probably somebody like [the Understanding Cinema film practitioners] and what [they] do in the life that they currently lead and their demographic, so that's really positive. (Conversation with author, 2016) 
I encountered further difficulties regarding the availability of suitable equipment. Most of the schools lacked their own cameras and struggled to secure funds to buy further equipment. Frequently a small number of cameras and laptops were shared among a whole school, leading to problems with equipment being unavailable, turning up uncharged or - worse - project files or footage being deleted off laptops while the equipment was used elsewhere in the school. I was particularly resistant to proposals students use iPads. Given the complexities involved in developing conscious approaches to camera placement (mentioned earlier in this article), I felt students required particularized equipment they could associate with new, clearly delineated functions. I was particularly wary that the rangy, lackadaisical approach to filming associated with the camera-phone spectator that I was so keen to help my students unlearn (whereby a camera is held at eye level, directly in front of the face, and follows a given action from wherever the spectator happens to be standing) might persist if they used smart technologies easily associated with other uses. I was unsuccessful in my arguments and some schools participated in the project almost entirely using iPads, which subsequently proved unsuitable even in ways I had not predicted: while one school purchased fixtures allowing iPads to sit uneasily upon tripods, the iPads frequently fell out of these fixtures onto the ground, and in general were unsuitable for filming outside (somewhat ironically given CCAJ's topic in 2015/16). Given data protection systems, it proved very complex to remove footage from the iPads to be watched on screen or edited in any way, and overall I had the distinct impression that participants were - as I had feared - unable to develop the same degree of self-consciousness regarding camera placement as the schools able to use small FlipVid cameras (whose sole function was to shoot video). A teacher who began the project with iPads, before securing access to cameras, described this:

[The students'] mindset is [that] iPads are for fun. They were given for educational purpose, but there's a lot of selfies taken on them.... The fact that [the iPads foster the] 'point-and-shoot thing', [meant] that [when] they went outside with the iPads, they'd just be like, 'film'. Whereas [with the cameras], when they went outside, they had to get the tripod up, get the height of it, clip it on, have a look, ... and also had to take it in turns to have a look, that kind of thing. That sort of physicality ... was really important. ... Also there's too many distractions on an iPad. If I get bored on an iPad, I flip it to a game and we all gather around and I play whatever. Whereas ... with the camera, they're like - okay, they're waiting maybe for someone to turn up, like 'let's have a look and see what that seagull looks like from afar'. (Conversation with author, 2016)

These broader ecological difficulties delivering Understanding Cinema in 2015/16 were significantly exacerbated by CCAJ's annual topic: 'Climate/Weather'. The 'Rules of the Game' comprised:

1. Students each making a Lumière Minute filming 'the weather where I live'.

2. A group of students making a short (2-minute) edited film or 'montage' conveying a weather event, and the sensations it gives rise to.

3. Students filming a short scene (2 minutes) of no more than two to three shots, in several contrasting weather conditions, at different points across the year, between October and March

4. Students filming a 5-7-minute short film, based 'around a love story or a friendship which contains: a shelter. This can be an urban shelter, a hiding place 
or a shelter constructed especially for the film. A scene of solitude or indecision, where the mis en scène, the dialogue and other considerations will be made in response to the weather on the day of filming. The elements of the weather that you experience when filming should be perceptible to the viewer.'

I quickly found 2015/16's topic did not provide the same degree of access to the fundamental ontology of cinema as 'The Long Take'. Rather than allowing an exploration of core cinematic parameters and primary modalities of filmmaking, 'weather' seemed a thematic, secondary modality; an element within the cinematic arena rather than one of the elements constituting it; an aspect of cinematic epistemology rather than cinematic ontology.

This lack of fundamental purchase also seemed reflected within the 'Rules of the Game': while Exercises 1 and 2 helped participants explore how cameras might articulate poetic sensibilities towards weather, they did not impart enough of the rudiments of cinema to subsequently allow my students to progress to shooting fuller cinematic ideas. Perhaps if the participating students had been those classes from Law, St Gabriel's and Broughton I had worked with in 2013/14, coming to the theme of weather pre-equipped with their learning from 'The Long Take', they would have been able to supplement their pre-existing, foundational knowledge with the additional exploration of secondary expressive parameters. In almost every instance, however, my classes in 2015/16 were encountering practical filmmaking for the first time, via an introductory route that in key respects seemed tangential and obscure. (Here, I encountered for the first time a sense that CCAJ seemed to assume, whether consciously or not, a degree of prior acquaintance with cinematic practice.)

I subsequently found there was an enormous leap in terms of cohesive learning chronology between the early poetic, impressionistic work of Exercises 1 and 2, and the requirements of shooting a dramatic scene, let alone an extended film. Further, I found that 'Climate/Weather' simply didn't engage my students. A 12-year-old student at Granton later described his feelings to me:

The weather stuff, we weren't really interested, because we didn't really think it was interesting until we got into the proper thing. That was the main thing that some of the boys and that in the class didn't like, the aspect of the weather, and just taking shots of that. (Conversation with author, 2016)

This scepticism was shared not only among students, but also among some of their teachers. One asked me:

'When did the long take [end]?' 'How do you think they managed to get that shot?' There was a lot of good conversation in that [topic]. We probably didn't do as much this time as that [with 'Weather']. Possibly the topic isn't as conducive because you go, right 'well why did they film in the weather' and they go 'because they want to make it sad'. That's basically it. It's less of a handle on it, because it's not such a technical thing and it's not actually how you set up the camera. It's more how you're using the elements to do things. It's a bit more, what would you call it? An esoteric type of thing, that sort of thing you can't grasp 'why'. It's just 'because'. (Conversation with author, 2016)

Here I encountered for the first but not last time a sense of, at times, congruent or divergent registers or vocalities within CCAJ: those expressed by the adults (and particularly by those leading the project) and those expressed by the students 
participating in it. When the project was functioning successfully, these different registers seemed relatively aligned and in constructive dialogue. During 2015/16, however, I noticed a disjunct akin almost to a culture clash, whereby adult ideas of what would engage children (informed, it seemed, by romantic conceptions of children's innate inquisitiveness towards the natural world) were significantly out of touch with what was genuinely able to engage young people. I have since noticed this divergence of registers elsewhere in CCAJ, such as in the harsh, condemnatory criticisms of children's film work that sometimes erupts during sharing sessions at the Cinémathèque Française, or during CCAJ screenings during which young children are expected to sit inside on long summer days listening to protracted discussions taking place via a translator. In 2015/16, this phenomenon seemed to manifest itself via a topic that neither provided students with direct purchase upon cinematic aesthetics, nor interested them thematically: problems I was to encounter again in 2017/18 and 2018/19.

I again allowed myself degrees of licence in interpreting the 'Rules of the Game', making an early decision to skip Exercise 3 altogether: given the broad range of difficulties I encountered in 2015/16, I felt the brief for Exercise 3 - involving children filming the same scene at different junctures during the year - was simply too ambitious. I couldn't see how it would fit within a graded chronology of learning whereby my students were expected to film a dramatic encounter early in the year, at a moment when they had shot poetic documentaries about weather but had as yet no knowledge of how to construct a dramatic scene. Given my students' difficulties engaging with the topic, I attempted to give them a head start by shooting all of the exercises first myself, in order to have concrete examples to discuss with them. I introduced an exercise of my own following Exercise 2, attempting to suture between the early expressive exercises

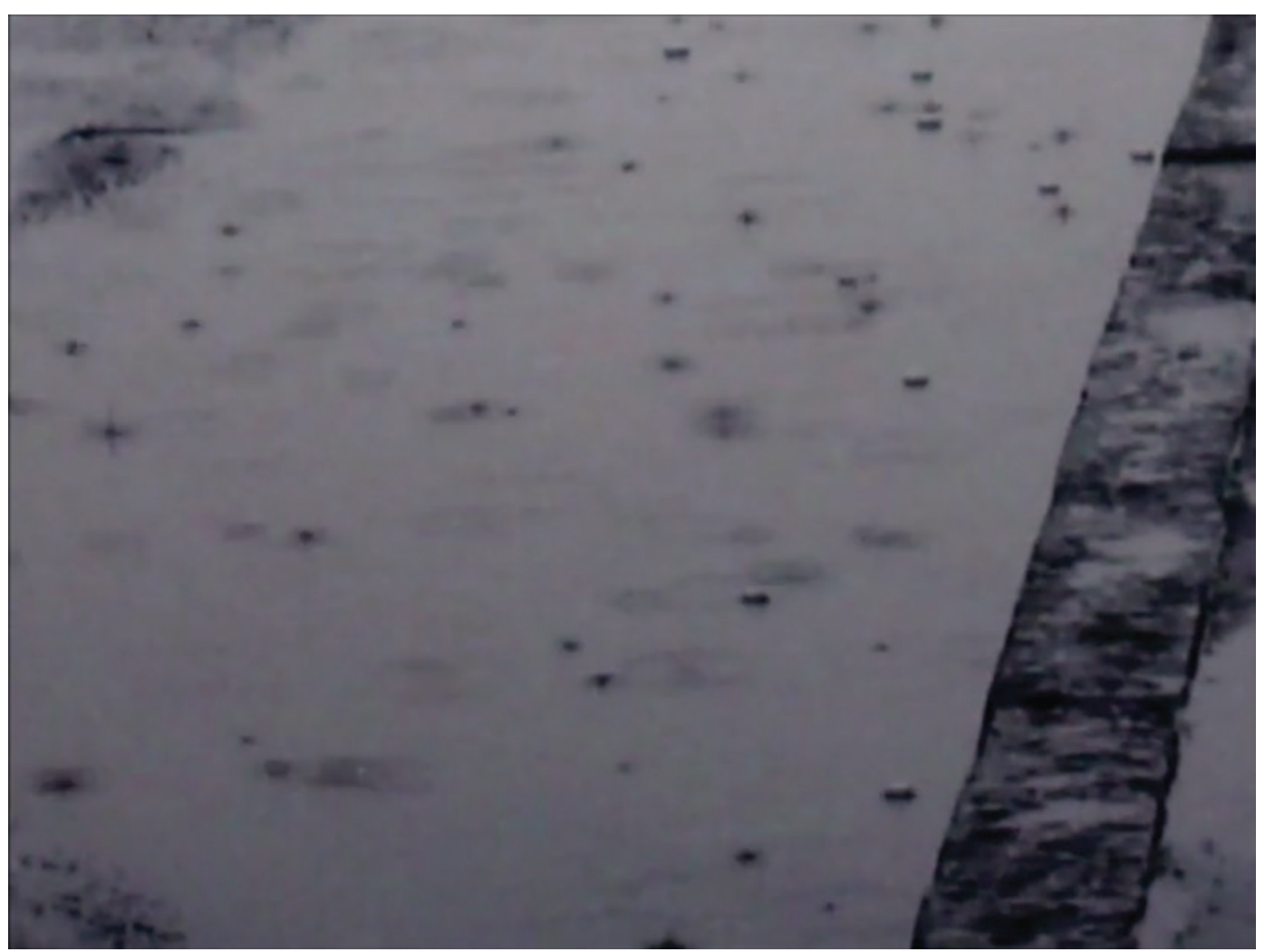

Figure 2: Weather as an expressive cinematic modality in Get Over It 
exploring weather and more directly dramatic scenes. Here I asked participants to insert a character into a scene involving a weather event, thus placing a human body (or - in Bressonian terms - a 'model' (Bresson, 1997: 14)) in counterpoint with the weather, to begin bridging between the more abstract weather documentary work the students had done in Exercises 1 and 2 and human-focused drama.

Despite these attempts, I still found that, when it came to filming final films, my students remained poorly equipped by the chronology of learning embodied within 2015/16's 'Rules of the Game' to progress to shooting more developed, dramatic ideas as part of a longer film. This struck me in particular when some of my younger students at St Mary's shot a conversation between two characters in a pair of reverse angles, stopping the camera to shift back and forth between camera positions after every line, thus using around twenty set-ups (highly divergent in framing and eyeline) to shoot a conversation that only required two! And yet, how could they be expected to know otherwise, when they had never filmed a conversation before?

One of the greatest struggles I encountered assisting participants with their final films was in encouraging my students to continue to include elements of weather in their work. As mentioned, participants viewed their final films as a chance to leave behind the 'boring' weather work they had been obligated to do earlier in the project and engage with more exciting, dramatic stories with greater relevance to their own lives. I therefore looked for gentle ways to reconcile the stories students were interested in telling with CCAJ's theme. Returning to my explorations in 2013/14, using montage to find points of suture and closer alignment between documentary footage and modest, naturalistic drama scenes, I encouraged my students to go back to the films they had made in Exercise 2 and conceive of dramatic narratives to stitch in between their expressive shots of weather. Here, I asked students simply to make a dramatic film using weather as an expressive element, removing all the further specifications provided by CCAJ for the final exercise (regarding 'a shelter' and so forth), which I worried would simply confuse and irritate my students at a delicate point in an already difficult process. This proved particularly successful in Granton's Get Over It, a film demonstrating considerable maturity in its exploration of the painful experience of coming out at primary school, in which weather is incorporated as a highly expressive element (see Figure 2). This approach also proved relatively successful for the lead group at St Mary's in their film The Park, which stitched a narrative about an encounter with a dangerous stranger into their ambient footage of a local park. As described in greater detail elsewhere (Chambers, 2019: 38), I experienced the greatest resistance encouraging my older students at WHEC to incorporate weather into their final film. In the assistance I gave the students with their edit I ended up myself crowbarring shots of weather into their film, to the scepticism and disapproval of the film's director - a decision I now look back on with significant discomfort.

Significantly, of the four schools I worked with in 2015/16, the only one able to finish the further group films (where I had not provided additional input) was Granton Primary School, where the teacher - Aoife Donnelly, a highly organized, motivated and engaged teacher (who went on to have considerable engagement with the project in future years; see Donnelly et al., 2018) - managed to supervise both the shoots and edits for the remaining films herself. Aoife was perhaps the only teacher for whom the 'weekon, week-off' model worked successfully. During my sessions Aoife would quietly take notes, before going on to oversee practical exercises the subsequent week with a notable degree of confidence and success. Aoife herself described the process as follows:

I know you [the film practitioner] were only able to come in every once a fortnight ... but actually it worked quite well that you were in one week 
and you set us a project and then I just went and did that the second week with them. So, I was just able to set a specific understanding [and a] similar timetable each week. (Conversation with author, 2016)

In conclusion, 2015/16 illustrated how challenging the same basic project structure could be when the pedagogical input from CCAJ lacked the same focus and relevance as it had done the previous year of my involvement, and where multiple ecological factors (such as the confidence of teachers, lack of class time and availability of appropriate equipment) rendered the educational settings somewhat fraught. Additionally, 2015/16 pointed to further problems with CCAJ's underlying methodology, which I will return to in my conclusion, regarding discordant different registers within the project and the assumption that participants had already familiarity with filmmaking.

\section{6/17: 'Play'}

The 2016/17 period of the project fortunately marked a return to a more successful delivery of Understanding Cinema. Responding to my evaluation, CMI reverted from 2015/16's 'week-on, week-off' structure to allowing filmmakers to again be present in classrooms every week. I was again able to work with Aoife Donnelly in Granton, the first time I had been able to work for more than a year with the same teacher. Understanding Cinema was delivered at Granton as an after-school club run by Aoife, her colleague Avril Whelan and myself for P6 (10-11-year-old) and P7 (11-12-year-old) students, on a voluntary, sign-up basis. We started the year with approximately thirty students and, while the group dwindled in numbers a little throughout the year, we retained a core, enthusiastic cohort who were subsequently chosen to represent Scotland at the 2017 CCAJ screenings in Paris. Alongside Granton, I worked with a small (20-student) P7 class of almost entirely female students at Lorne Primary School in Leith, with an experienced, engaged teacher. Both schools had pre-existing access to a sufficient supply of FlipVid cameras and basic editing equipment (Windows Movie Maker).

Significantly, I was given the opportunity by CMI in 2016/17 not only to attend the training sessions at Cinémathèque Française, but also to participate in shaping the 'Rules of the Game' as they were subsequently followed in Scotland. I quickly had misgivings about CCAJ's annual topic, 'Play', another secondary modality of cinema that was thematic rather than fundamental, epistemological rather than ontological. After my experiences with CCAJ's divergent adult/student registers in 'Climate/ Weather' I was particularly concerned 'Play' might entail adults attempting to impose idealized conceptions and command performances of play upon the project's younger participants.

The 2016/17 'Rules of the Game' were initially delivered to us during training sessions in Paris as follows:

1. Participants individually choose a game they like (played by one or more children, it can be a whole game or just a moment of a game) and film it in a documentary manner, using one shot (max 2 mins).

2. In small groups, participants film the following scenario as a short (2-min max) film using either one or several shots: two children are thrown out of class by their teacher. They are put into a small space and make a game out of what they find there, using their bodies, the space and objects.

3. In small groups, film the following scene ( $\max 2$ mins) using as many shots as appropriate: one person loses their spatial recognition (e.g. they get dizzy). This is reflected in the acting and the way it is filmed. 
4. Make a film (5-10 mins max) where the story is interrupted at a certain moment, when a character finds their freedom through playing which allows them to escape from the confines of their everyday reality. Music, sound, space, montage are all part of how this is expressed.

Drawing upon my concerns from 2015/16 regarding the importance of establishing a chronology of learning with clear, progressive learning objectives to each exercise (while also opening up access to the core, ontological parameters of cinema), I was subsequently able to make several early interventions as to how the 'Rules of the Game' were shaped in Scotland. Leaving Exercise 1 roughly the same, I added additional elements to Exercise 2 to afford students the opportunity to learn how to structure a scene through different shots. Initially, students were asked to film the scene themselves, without adult involvement. The results of these shots were then to be screened and discussed among the class, with specific attention paid to camera placement. Students were subsequently asked to shoot the scene again, this time using a series of seven still photographs, which carefully considered what was seen and where it was seen from (for which I took inspiration from Bergala's account of the practice of Jean-Luc Lhuillier (Bergala, 2016: 108)). Finally, students were asked to film the scene again now using moving images, which also subsequently allowed them to explore early experiences of editing. My intention here was that Exercise 2 - while allowing participants to explore cinematic expressions of play - would simultaneously enable them to begin thinking about how to construct a scene, an aspect of learning chronology sorely lacking in 2015/16.

I made a further intervention regarding Exercise 3, specifying that participants should shoot a scene of play first from an:

objective, 'external' perspective, where the camera does not participate in the play: a 'third person camera', and secondly from a 'subjective, internal' perspective, where the camera is involved in the play. This is a first or second person camera, where we see through the eyes of the main character, or someone involved in the play with him/her.

Here I hoped that, while furthering their experiences of filming play, Exercise 3 would simultaneously allow participants to explore core modalities of cinema, in terms of subjective/objective camera perspectives and the point-of-view shot. Finally, I provided students with the option simply to make a final film where a scene of play formed a core part of the narrative, if the proposed scenario proved too prescriptive.

My fears that 2016/17's theme would forcibly interpolate images of play from its younger participants were happily proven wrong early in the delivery of the project at both Granton and Lorne. Participants responded enthusiastically and unselfconsciously to CCAJ's invitation to play (and film each other playing). Recalling the notion of different registers and vocalities within CCAJ, the success of 2016/17 seemed largely due to the ability of 'Play' to speak directly to experiences participants themselves valued, which emerged organically from their own lives. Where 'Climate/Weather' had felt distant and abstract, 'Play' was immediate, readily present and acknowledged within the lives of CCAJ's participants, and thus a ready source of expressive material. Asking children to film scenes of play thus - in my experiences at least - proved happily organic in a way that asking them to explore poetic sensibilities upon weather (which most of my students found boring and mundane) had not.

Our revised 'Rules of the Game' seemed to work well, with Exercise 3 in particular allowing students valuable opportunities to experiment playfully with camera placement. A more granular account of our work using these exercises at Granton Primary School from the perspective of the teachers involved can be found in 'See You Tomorrow: 
A case study of the Understanding Cinema project at Granton Primary School in Edinburgh' (Donnelly et al., 2018), which focuses upon the making of one of the final films made by Granton's after-school club. A sensitive representation of experiences of racism within the school playground, See You Tomorrow was the second of Granton's CCAJ films to explore serious, real-life issues within the lives of its participants. Taken alongside Get Over It's earlier exploration of homophobia, and subsequent films The Strada (exploring students' real-life experiences of immigration and integrating into a new community) and Dancing is for Girls (exploring the stifling presence of gender norms within the classroom), Granton's remarkable corpus of Understanding Cinema films between 2015 and 2019 provides further testament to the power of cinema as a means of fostering emotional literacy, assisting students in exploring difficult issues performatively within the relatively safe, empowering arena of film. Notably, See You Tomorrow similarly provided further evidence of neorealist approaches to children's film production leading to increased self-efficacy, with the film's lead actress noticeably gaining in social confidence through her experiences acting in the film, as corroborated both by her teachers and in her own words (Donnelly et al., 2018: 75).

Significantly, Granton managed to complete all four of the films developed by groups in their after-school club. While I lent additional input to the shooting of See You Tomorrow and In My World, Aoife and Avril themselves managed to oversee the shoots for two further films: Try Outs and Friends Forever. While I edited all four of Granton's films on a home system, my students at Lorne were able to edit their films themselves at school on Windows Movie Maker (having engaged enthusiastically with the introductory editing work we undertook as part of Exercise 2) with only minimal tweaks and polishing from me. (A fuller account of the co-creative process I undertook with students from Lorne on Not Going Anywhere can be found in Chambers, 2019.) Alongside their independence in the edit, Not Going Anywhere was shot entirely without my presence on set. While Lorne did not manage to finish all four of the films developed within the class, a full second film, Mixed Feelings, was shot, again with very little contribution from me, clear evidence of a strong engagement with the project.

\section{Conclusion}

The very notion of an experimental pedagogy implies that the real possibility of a failed pedagogy is always close at hand. Ultimately, my experience delivering CCAJ in Scottish classrooms has been that while the project regularly delivers upon the utopian promise described by Reid (2018) - in its visionary, holistic intertwining of the creative, the critical and the cultural (BFI, 2015) (and the stimulating, generous forum it creates for international film education practitioners to share and discuss practice) this promise was frequently undermined within a complex tangle of factors. Here, the familiar metaphor of a seedling and soil is useful in illuminating the interaction between pedagogical and ecological factors: the year-to-year success of CCAJ can be seen to depend as much upon the seed (the pedagogical affordances generated by CCAJ's annual curriculum) as upon the soil (the broader context within which that pedagogy attempted to take root). Reflecting upon the complex ecologies in which I have delivered Understanding Cinema over the past five years, it is unfair to ascribe the relative dissonances I encountered in 2015/16 (and subsequently in 2017/18 and 2018/19) to internal difficulties within CCAJ alone. The availability and scale of funding, the age and disposition of the students I was working with, how frequently and for how long I was able to spend with students each week, the easy availability of locations to film in, the availability of appropriate equipment, the dispositions of participating 
teachers and senior management, and wildly uncontrollable factors such as the weather all played a factor in either affording or restricting possibilities for children to make a considered engagement with cinema. Frequently I had the experience, on any given day with CCAJ, of attempting to navigate a series of obstacles - no available school spaces to film in, camera batteries uncharged, broken tripods, bad weather, difficulties in student concentration and comprehension, disagreements between students, absence of key personnel - in order to reach the crucial moments in which I could open up spaces of comprehension, exploration and agency for a small number of participants. Given the degree of personal interpretation I have detailed herewith, my own ability and level of initiative as a film education practitioner in responding to the contingencies of each situation was undoubtedly also a delimiting factor.

My final two years of Understanding Cinema served to confirm many of my criticisms regarding CCAJ's frequently frustrated potential, and the extent to which the project's annual topic served - or, more often, failed to serve - as a suitable initial point of access for participants into film culture (either through affording direct entry routes to core cinematic ontology (as in the case of 'The Long Take') or through a thematic focus finding an easy resonance within students' lives (as with 'Play')). In 2017/18, 'Places and their Stories' again explored a thematic, secondary modality (with many of the same difficulties as 'Climate/Weather') with which younger participants found it difficult to engage. Furthermore, after structural and personnel changes at $\mathrm{CMI}$, I was unable to have the same shaping influence upon the 'Rules of the Game' I had had in 2016/17. The focus upon 'place' led to expectations students would spend much of their time outside the classroom, on location, in sites that held significance for them; expectations that unfortunately proved problematic and created various administrative and logistical obstacles involved with taking students outside school grounds, such as disclosure checks and asthma training. I quickly found at both schools I worked with that trying to take the whole class out at one time was near impossible. I thus began, over the course of the year, to take ever-smaller groups of students out to film, subsequently finding that - as many of the locations the children wanted to film in were some distance away from school premises - we often spent at least 50 per cent of our time together walking to and from school. While Understanding Cinema 2017/18 again produced some strong material - such as Granton's Lobstercatcher and The Strada, and Lorne's Meet Me in the Park - the groups of students I worked with were small and I had to intervene in the creative process significantly more than I had done in previous years, and - significantly - none of the films other than those for which I was able to provide additional input were finished.

In the final year of my involvement, Understanding Cinema's 2018/19 topic was 'The Situation', perhaps CCAJ's most abstract, inscrutable theme in my experience working with the project yet. Again at Granton, I found myself working with Aoife Donnelly's new P4 class (8-9 year olds), in parallel with a second P4 class led by Aoife's colleague. At CMI's direction I returned to a week-on, week-off structure (a notable difference to $2015 / 16$ here being that Aoife herself was able to offer ongoing support to her colleague in the weeks I was not present). Unfortunately, we again quickly found that both P4 classes, while highly enthusiastic, had difficulties developing the concentration required for detailed filmmaking tasks, and were possibly too young to participate in the project given the abstract topic. We adopted a highly formalized routine, breaking up time spent sitting and listening in the classroom with time spent outside filming. While in earlier years of the project I had left practical work to take place at moments when I was not in class, it became clear to us that a sufficient diversity of activities was needed within a single session in order to cater to children's attention spans. The 
'Rules of the Game' of 2018/19 - in places as inscrutable as the theme (one exercise involving children providing audio soundtracks to a series of classic paintings) - proved highly challenging for our students and, after discussion with Aoife and her colleague, we went relatively off-piste to adopt a simplified methodology, through small, simple practical exercises geared towards very basic learning objectives (such as filming a close-up, or filming a pan). Both students and teachers struggled to comprehend 'The Situation' and some of our attempts in class to discuss or use the theme as a point of departure for story generation bordered on the absurd: to my question of 'tell me about a situation that you yourself have been in recently', students were able to answer almost anything and frequently did. As always at Granton, the project produced some strong final films - Don't Sleep In and Dancing is for Girls - both growing from cocreative script sessions in which I would encourage students to brainstorm ideas, before helping them shape their more appropriate ideas into feasible scripts. Like 2017/18, however, both films were again made with very small groups and required an even greater degree of co-creative input from me than subsequent years. Again, none of the films developed by other groups were completed.

In 2020, 26 years since its inception, CCAJ's 'experimental', open-ended approach and resistance to repetition and systematization arguably risk a growing sense of the impractical and the impossible; it is becoming a process of relentless innovation forced to explore increasingly obscure, secondary parameters of cinema that - in turn - prove increasingly incompatible with schools engaging with cine-literacy and filmmaking activities for the first time. As one of the participating teachers in 2015/16 remarked of her students at the start of the school year, 'these kids have never touched a camera like that before so you want them to go out and play with shots. You want them to just see what mistakes they make' (Conversation with author, 2016). Given CCAJ's recent emphasis upon increasingly abstract, secondary cinematic modalities (such as 'The Situation') rather than core, formal properties of cinema (such as 'The Long Take'), it would seem that the primary modalities that can be explored within any given medium are not an inexhaustible list. Simultaneously, there would seem a correspondent, semi-solipsistic risk that CCAJ's topics are structured around the implicit (perhaps unconscious) assumption participants all begin their engagement with the annual topic from a pre-existing degree of cine-literacy, because this is the case for those leading the project. Here again, the project would seem to risk privileging the perspective of its continuing adult participants, rather than the students who usually find themselves at the start of an academic year encountering CCAJ for the first time. As an ongoing programme with a deep history, in constant pursuit of uncharted territory, CCAJ cannot help embodying an implicit, cumulative sense of progression for those who remain involved, which it is subsequently increasingly difficult for schools to come to cold.

Returning to the Scottish context in which I write, informed by its own particular predicament and preoccupations, it would seem increasingly that small nations wishing to root foundational engagements with film within complex ecologies would be advised simultaneously to distinguish between and learn from CCAJ's peerless strengths and its significant weaknesses. On one hand, it cannot be emphasized strongly enough that CCAJ's approach is, in my experience, unparalleled in its holistic embrace of the interlocking cultural, critical and creative parameters of cinema, and in this respect almost all other film education programmes within the UK suffer by comparison. As in the case of 2013/14, CCAJ at its best allows participants encountering cinema for the first time to plug directly into fundamental questions of film aesthetics, in conversation with a diverse, carefully curated body of work from global film culture, in a manner frequently demonstrating remarkable results (Chambers, 2018; Donnelly et al., 2018). 
On its own terms, however, I argue CCAJ is not an initiative best suited to building foundational cine-literacy in schools encountering film education for the first time, given its disinterest in consolidating, systematizing or repeating aspects of its approach. Given the attendant possibility of failure within an experimental pedagogy there is consequently little assurance whether any given school choosing to participate in CCAJ for the first time will encounter the relative strengths of 'The Long Take' or the relative weaknesses of 'The Situation'.

There is surely a middle ground, however, between a relentless pursuit of progress that risks wantonly discarding the findings it encounters en route, and the sedimented repetition of tired, ossified pedagogies. As a film scholar, my own, admittedly ignorant, conception of 'experiments' is that they subsequently involve analysis, consideration and consolidation of their findings; and, perhaps even - where results are particularly compelling - the recommendation of wider adoptions of practice. Does there not then exist a powerful possibility of gleaning some of the many valuable findings from CCAJ's experimental approach; of stopping to consider the things that did work, that were successful within CCAJ's many annual experiments - rather than simply proceeding to the next experiment? And through such a process of consolidation, could something not be shaped and outputted that could subsequently be repeated in other schools elsewhere, so that others too could share and benefit from what has been found and learnt through CCAJ's experimental pedagogy? There have been several mentions within the pages of this journal of a 'film education for all': surely the riches uncovered by CCAJ's annual adventure must be shared more widely than the relatively small community of teachers and students able to participate internationally each year?

While continued participation in CCAJ undoubtedly provides a valuable corrective for film education practitioners in Scotland to keep their pedagogical assumptions in check and their horizons open (alongside the welcome opportunity to connect with a generous international community of practice), to continue prioritizing exploration over consolidation would seem to risk wasting resources that, in Scotland, are sadly all too limited. It is very possible that French film education and French film culture more generally are sufficiently sturdy not to require any such process of consolidation. In Scotland (and more widely in the UK), however, where film culture is in more urgent need of the sort of powerful intervention many of CCAJ's findings might well help catalyse, such a process of consolidation, of gathering together and sifting through the invaluable knowledge generated through experimental pedagogical processes, seems imperative. Such a step is yet to be taken, and it is the concluding contention of this paper that such efforts are urgent and essential.

\section{Acknowledgements}

I would like to thank Nathalie Bourgeois for her generosity, both in talking to me in the early preparatory work for this paper and - more broadly speaking - for the considerable generosity she and her team have extended and continue to extend to their international collaborators in CCAJ. I hope that my more critical reflections herewith are taken with the considerable good faith and admiration with which they are intended, and within the rigorous, questioning spirit of an 'experimental pedagogy'.

\section{Notes on the contributor}

Jamie Chambers is a lecturer in film and television at Edinburgh College of Art. He is the founding editor of the Film Education Journal and has worked as a film education 
practitioner with Understanding Cinema and Cinéma Cent Ans De Jeunesse since 2013. He is the curator of the Folk Film Gathering (the world's first folk film festival (www. folkfilmgathering.com)) and is the director of the award-winning, BAFTA-nominated films When the Song Dies (2012) and Blackbird (2013).

\section{Filmography}

- 2013/14: The Long Take

Blocked (UK, Jack Hamilton) - http://vimeo.com/groups/257525/videos/103998120

Blue Raspberry (UK, Bridget Harley) - https://vimeo.com/100150741

The Den (UK, Eve Duncan, Zoe Gormley, Sophie Hetherington, Alex Kane, Reon McSherry) https://vimeo.com/100796087

First Day (UK, Max Mayer) - http://vimeo.com/groups/257525/videos/103998121

Hide and Seek (UK, Alicia Jankowska) - https://vimeo.com/100796089

$L<3$ B (UK, Luke Davies) - https://vimeo.com/100150740

Me and Mum (UK, Jamie Thomson) - https://vimeo.com/groups/257525/videos/103997956

Wednesday (UK, Connal Tolmie) - https://vimeo.com/100796088

- 2015/16: Climate/Weather

Get Over It (UK, Granton Primary School) - https://vimeo.com/170974213

The Park (UK, St Mary's RC) - https://vimeo.com/174234809

Passing Clouds (UK, St Joseph's RC) - https://vimeo.com/169701498

Yes Sir (UK, WHEC) - https://vimeo.com/169730286

- 2016/17: Play

Friends Forever (UK, Granton Primary School) - https://www.youtube.com/ watch?v=UgKfwKEtG9I\&list=PLxYOCwOFv2odbk9LxVenqfBPIchrJSIMC\&index=17

In My World (UK, Granton Primary School) - https://www.youtube.com/ watch?v=2cdV103COTY\&list=PLxYQCwOFv2odbk9LxVenqfBPIchrJSIMC\&index $=23$

Mixed Feelings (UK, Lorne Primary School) - https://www.youtube.com/watch?v=QUtFPVO_ Hqs\&list=PLxYOCwOFv2odbk9LxVenqfBPIchrJSIMC\&index $=18$

Not Going Anywhere (UK, Lorne Primary School) - https://www.youtube.com/ watch?v=vBWmw7FDd0s\&list $=$ PLxYQCwOFv2odbk9LxVenqfBPIchrJSIMC\&index $=21$ See You Tomorrow (UK, Granton Primary School) - https://vimeo.com/221750662 Try Outs (UK, Granton Primary School) - https://www.youtube.com/ watch?v=w164usi03bM\&list=PLxYOCw0Fv2odbk9LxVenqfBPIchrJSIMC\&index $=16$

- 2017/18: Places and their Stories

Lobstercatcher (UK, Granton Primary School) - https://www.youtube.com/ watch?v=h7duUw0NkQA\&list=PLxYQCw0Fv2odbk9LxVenqfBPIchrJSIMC\&index $=14$

Meet Me in the Park (UK, Lorne Primary School) - https://www.youtube.com/ watch? $v=$ Ebm0tIMnHnc\&list=PLxYQCwOFv2odbk9LxVenqfBPIchrJSIMC\&index $=12$

The Strada (UK, Granton Primary School) - https://www.youtube.com/ watch? $v=q$ EjHUcD15Eo\&list $=$ PLxYQCwOFv2odbk9LxVenqfBPIchrJSIMC\&index $=11 \& \mathrm{~s}=46 \mathrm{~s}$

- 2018/19: The Situation

Dancing is for Girls (UK, Granton Primary School) - https://www.youtube.com/ watch?v=1V88G5zaSNI\&list=PLxYQCwOFv2odbk9LxVenqfBPIchrJSIMC\&index=4

Don't Sleep In (UK, Granton Primary School) - https://www.youtube.com/ watch?v=BLbrCEAK584\&list=PLxYQCwOFv2odbk9LxVenqfBPIchrJSIMC\&index $=7 \& t=0 \mathrm{~s}$

\section{References}

Aidelman, N. and Colell, L. (2018) 'Transmitting cinema: Some proposals for our time'. Film Education Journal, 1 (2), 147-62. Online. https://doi.org/10.18546/FEJ.01.2.04.

Bachmann, A. and Zahn, M. (2018) 'Film education as a multiplicity of practices: A media-ecological perspective'. Film Education Journal, 1 (1), 78-89. Online. https://doi.org/10.18546/FEJ.01.1.07. 
Bergala, A. (2016) The Cinema Hypothesis: Teaching cinema in the classroom and beyond (FilmmuseumSynemaPublikationen 28). Trans. Whittle, M. Vienna: Austrian Film Museum.

BFI (British Film Institute) (2015) 'A framework for film education'. Online. https://tinyurl.com/ yex2qy3v (accessed 17 April 2020).

BFI Southbank (2017) 'The Cinema Hypothesis - Alain Bergala symposium [video]'. Online. www. youtube.com/watch?v=COH74quQWJ8 (accessed 15 September 2020).

Bresson, R. (1997) Notes on the Cinematographer. Copenhagen: Green Integer.

Buckingham, D. (2003) Media Education: Literacy, learning and contemporary culture. Cambridge: Polity Press.

Burn, A. (2018) 'Reflections on The Cinema Hypothesis: A response to Alain Bergala'. Film Education Journal, 1 (1), 51-63. Online. https://doi.org/10.18546/FEJ.01.1.05.

Cannon, M. (2018) Digital Media in Education: Teaching, learning and literacy practices with young learners. London: Palgrave Macmillan.

Chambers, J. (2018) 'Towards an open cinema: Revisiting Alain Bergala's The Cinema Hypothesis within a global field of film education'. Film Education Journal, 1 (1), 35-50. Online. https://doi.org/10.18546/FEJ.01.1.04.

Chambers, J. (2019) 'Exploring co-creation in practical film education from primary school to postgraduate study: Theoretical and auto-ethnographic perspectives upon teaching film practice'. Film Education Journal, 2 (1), 27-47. Online. https://doi.org/10.18546/FEJ.02.1.03.

Chambers, J. (forthcoming) '"We know what it's actually like": Voice, dialect and self-efficacy in Scotland's Understanding Cinema project'. In Lury, K. (ed.) The Child and Film. London: BFI and Bloomsbury.

Cinéma Cent Ans De Jeunesse (2020). 'Questions of cinema'. Online. www.cinematheque.fr/ cinema100ansdejeunesse/en/resources/all-the-questions.html (accessed 17 April 2020).

Cousins, M. (2006) '"... And now, it's over?" The problem with Scottish cinema'. The Drouth, 200 (20), 11-22.

Donald, S. (2019) 'Follow the yellow brick road: The passeur, the gatekeeper and the young migrant film-maker'. Film Education Journal, 2 (1), 48-61. Online. https://doi.org/10.18546/FEJ.02.1.04.

Donnelly, A., Whelan, A. and Chambers, J. (2018). 'See You Tomorrow: A case study of the Understanding Cinema project at Granton Primary School in Edinburgh'. Film Education Journal, 1 (1), 64-77. Online. https://doi.org/10.18546/FEJ.01.1.06.

Eckert, L. and Martin, S. (2018) 'Film education and age(ing): A case study of a university course on FilmBildung'. Film Education Journal, 1 (2), 163-79. Online. https://doi.org/10.18546/FEJ.01.2.05.

Gibbs, A. (2018) 'Film education otherwise: A response to Bergala's dialectics of cinema and schooling'. Film Education Journal, 1 (1), 90-100. Online. https://doi.org/10.18546/FEJ.01.1.08.

Giovacchini, S. and Sklar, R. (2011). Global Neorealism. Jackson: University Press of Mississippi.

Henzler, B. (2018). 'Education à l'image and Medienkompetenz: On the discourses and practices of film education in France and Germany'. Film Education Journal, 1 (1), 16-34. Online. https://doi.org/10.18546/FEJ.01.1.03.

Lacan, J. (1978) The Four Fundamental Concepts of Psycho-Analysis. Trans. Sheridan, A. New York: Norton.

McArthur, C. (1982) Scotch Reels. London: BFI Publishing.

Reid, M. (2018) 'Film education in Europe: National cultures or European identity?' Film Education Journal, 1 (1), 5-15. Online. https://doi.org/10.18546/FEJ.01.1.02.

Scottish Parliament (2013) 'Education and Culture Committee: Official report' (Tuesday 26 November). Online. www. parliament.scot/parliamentarybusiness/CurrentCommittees/71508. aspx (accessed 6 August 2020).

Skills Development Scotland (2019) Scotland's screen skills research - Summary. Online. www.centreforworkbasedlearning.co.uk/media/1649/screen-report.pdf (accessed 17 April 2020).

Slatinšek, P. (2020) 'Applying Alain Bergala's "three-phase" model to the history and development of film education in Slovenia'. Film Education Journal, 3 (1), 78-86. Online. https://doi.org/10.14324/FEJ.03.1.06. 